\title{
Research Synthesis For Adaptive Mentorship ${ }^{\circledR}$
}

Edwin G. Ralph, University of Saskatchewan, Canada

Keith D. Walker, University of Saskatchewan, Canada

\begin{abstract}
Adaptive Mentorship ${ }^{\odot}$ (AM) is a mentoring model the authors have developed over a 21-year period. Mentor-protégé pairs originally applied it in teacher-education internship programs; however, the authors have subsequently witnessed its adoption by other mentorship/coaching practitioners/researchers across the professions.

In this report, the authors describe AM, its rationale, implementation, strengths, and limitations and they synthesize the latest findings regarding its effectiveness as a tool in mentoring teachercandidates.
\end{abstract}

Keywords: Mentoring; Adaptive Mentorship; Practicum

\section{INTRODUCTION}

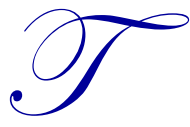

he benefits of mentorship have been well-documented (Kelly, 2007); however, persistent difficulties within the mentoring relationship have been repeatedly identified (Rose Ragins \& Kram, 2007; Roycraft, 2014). In an effort to enhance mentorship and address such weaknesses within the authors' own mentorship/supervisory program with teacher candidates, they designed Adaptive Mentorship $(\mathrm{AM})^{\odot}$, which is a mentoring model that they refined during the past two decades (Ralph \& Walker, 2011, 2013b). Initially calling it Contextual Supervision (CS, Ralph, 1998, 2005), the authors based it on contingency leadership principles (e.g., Hersey \& Blanchard, 1988).

\section{BACKGROUND}

In the model, the authors conceptualized mentorship as a developmental process by which an individual with more knowledge and skill in a field (i.e., the mentor) assists a person with less knowledge and skill in that field (i.e., the protégé) to develop in these areas (Ralph \& Walker, 2011; 2013a, p. 1; Allen \& Eby, 2007). With AM, mentors adjust their mentoring responses to match protégés' task-specific development level while coaching them in their learning setting. See Figure 1.

The authors have shown (Ralph \& Walker 2013b, p. 2) that the outer border of the diagram represents the overall physical, psychological, social, organizational, and cultural context within which the mentorship process functions. Many of these contextual factors cannot be changed by the pair, but they can change their own actions. Thus, mentors can modify their mentorship behaviour, which consists of two dimensions shown in Figure 1: (a) their "task" response (i.e., the degree of specific direction given to the protégé regarding the technical, mechanical, or procedural aspect of the latter's performance of the task being learned) and (b) their "support" response (i.e., the degree of "human" or psycho/social/emotional expression they provide the protégé learning the skill-set).

Moreover, the factor over which protégés have most control is their task-specific developmental level. It likewise consists of two dimensions - their "competence" level (i.e., their actual technical ability to perform the task in question) and their "confidence" level (i.e., their degree of self-assurance, composure, psychological comfort, and security and/or safety in performing the skill-set). 


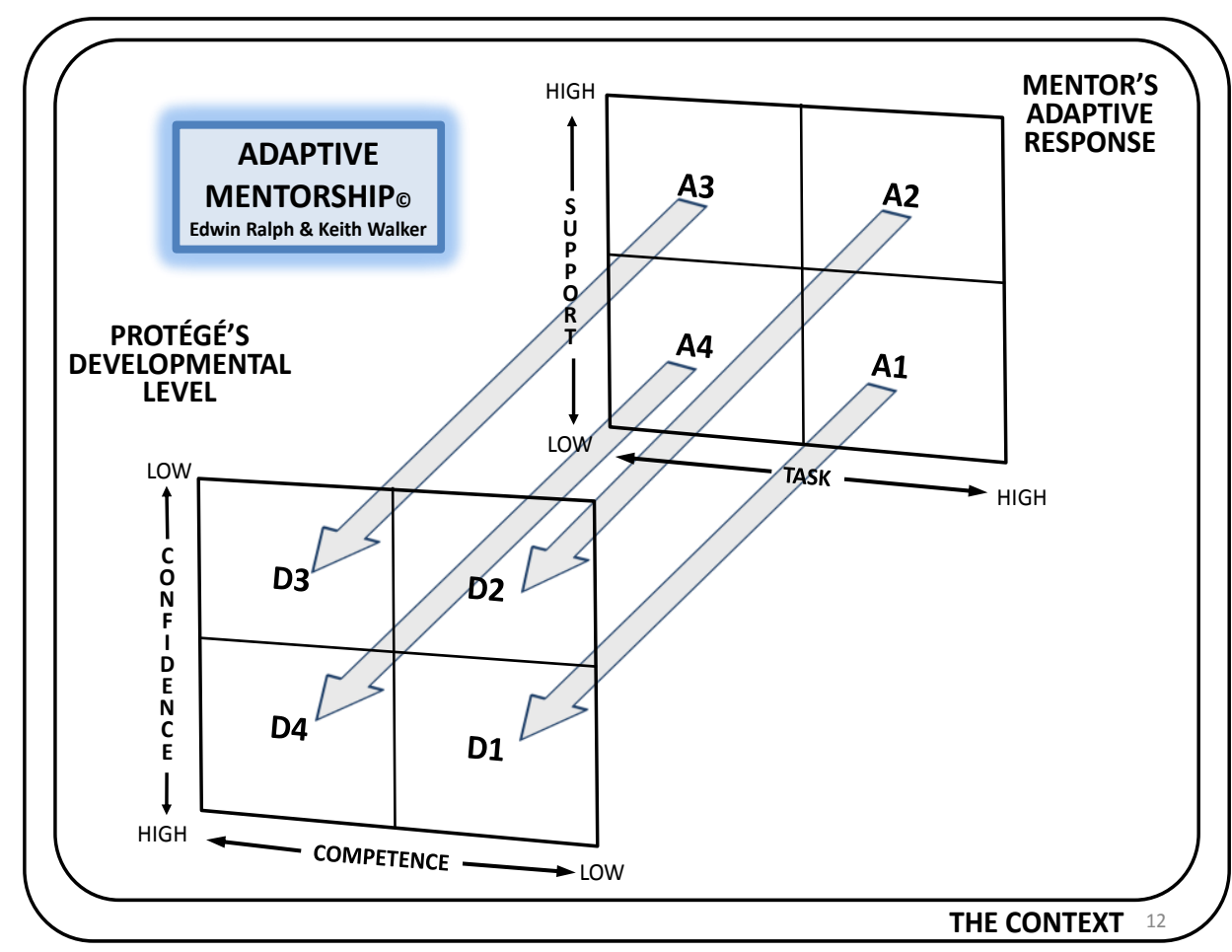

Figure 1: Adaptive Mentorship ${ }^{\odot}$ (Mentor Matches His/Her Adaptive Response to Synchronize with the Skill-Specific Developmental Level of His/Her Protégé)

The heart of the AM model is represented by the shaded arrows linking the D- and A-grids, which portray the mentor's matching of one of four typical "A" (adaptive) responses with a similarly numbered "D" (developmental) level characterizing the protégé's performance of the particular skill/competency. Of course, there are many more than four positions within each grid because there is a host of possible A/D combinations. However, for conceptual/analytical purposes, the authors highlighted these four combinations simply to reflect basic types within each quadrant.

\section{IMPLEMENTING ADAPTIVE MENTORSHIP ${ }^{\odot}$}

Mentorship pairs may apply AM using three steps (Ralph \& Walker, 2010, pp. 207-208):

1. Determine Protégé's Development: First, the protégé/mentor pair ascertains the existing development level of the protégé to perform a specific skill-set being learned at the time. As illustrated in the "D-grid," a protégé's task-specific level of development consists of both his/her competence and his/her confidence levels to perform the task. The D1 quadrant reflects an individual with "low competence" and "high confidence" to accomplish the task (i.e., he/she does not know exactly how to perform it but is confident, willing, and eager to try). A protégé at D2 is low on both competence and confidence, a protégé at D3 shows higher competence and lower confidence, and a protégé at D4 is high on both dimensions for the particular skill-set.

A protégé's developmental level may be identified: (a) by the mentor's formal and informal observations of the protégé's actual performance of the skill/task, (b) by the pairs' informal conversations about the protégé's D-level, and (c) by the protégé's answers to the mentor's direct questions about his/her progress. D-levels are task-specific, changeable over-time, different for different skill-sets, and temporary indicators of a protégé's stage at a specific point in time (Ralph, 1998, 2002, 2005; Ralph \& Walker, 2010, p. 207; 2013b, p. 78). 
2. Synchronize Mentor's Response: Next, the mentor appropriately adjusts his/her mentorship response to match the existing D-level of the protégé regarding the particular competency - A1 matches D1, A2 matches D2, and so on. The mentor's "A" adaptive-response also has two dimensions, the first of which is the degree of support the mentor provides (i.e., the psycho-emotional aspects of encouragement, reinforcement, and praise to bolster the protégé as he/she attempts to develop the particular skill-set). Support consists of genuinely positive words and/or actions and varies along a continuum. The second Aelement is task (i.e., how directive the mentor is toward the protégé regarding his/her technical or mechanical prowess in the task), which also varies along a continuum, ranging, for example, from telling, to demonstrating, suggesting, questioning, or delegating with respect to the protégé's skill-specific technique.

The key principle for the mentor to correctly match the A and D quadrants is that his/her task response must be inverse in magnitude to the extent of the protégé's competence level and, simultaneously, the extent of the mentor's support is similarly inversely proportional to the novice's level of confidence for a particular task.

3. Monitor Protégé's Development: Then the mentorship pair continually and mutually monitors the protégé's ongoing level of development, which necessitates that the mentor simultaneously adjusts his/her adaptive response to match, in inverse proportions, the protégé's changing development level(s).

\section{RESEARCH METHODOLOGY}

The authors conducted the research on the model with pre-service teachers and their mentors in the internship component of their teacher-education program (Ralph, 2005; Ralph \& Walker, 2011, 2013a, 2013b). The core skill-sets for beginning teachers to master included planning, presenting, questioning, responding, classroom management, and assessing student learning. During the internship, protégés develop their competencies in these areas under the tutelage of their mentors, who provided them with ongoing feedback and support as they engaged in real-world school-based settings.

The methodology the authors used to gather data regarding the effects of AM helped determine how effectively the mentors appropriately synchronized their mentoring/leadership responses (i.e., mentors' A-positions) in order to match the protégé's existing task-specific developmental levels (i.e., protégés' D-locations).

The authors then gathered a record of these matches by having participants mark, on hard copies of the two grids, the locations that best represented the where they and their partners were located within the respective A and D quadrants for a specific teaching competency at a specific point in time (Ralph, 2004, p. 159; 2005, p. 277; Ralph \& Walker, 2010, p. 210). Thus, on a blank A- and on a blank D-quadrant-sheet, each partner independently wrote an $\mathrm{X}$ at his/her respective location on the one sheet and that of his/her partner on the other sheet with respect to the mentoring process for the competency of classroom management at that specific period in the practicum. The authors focused on classroom management because it has repeatedly been identified as an essential instructional skill-set that all effective teachers must master (Burden \& Byrd, 2012; Seeman, 2010).

Thus, cooperating teachers would privately place an $\mathrm{X}$ in one of the $\mathrm{D}$ quadrants that they felt best reflected the existing developmental level of his/her protégé in terms of the latter's then-current ability in managing the learning environment. At the same time, protégés placed an $\mathrm{X}$ on their $\mathrm{D}$-sheets in the quadrant that indicated where they judged their performance level to be for the skill set of classroom management at that time in the practicum; then the pair shared their respective D-markings and their rationale for the selection.

Next, each partner independently marked an $\mathrm{X}$ on their respective A-grid sheets that best reflected their view of the mentor's response-style in terms of how the latter mentored the protége for classroom management at that point; then partners shared and defended their respective A-plottings with each other. Finally, the authors collected, collated, and analyzed these data sheets, calculating the extent that pairs comprising the cohort matched their self- and partner-choices. 


\section{RESEARCH RESULTS}

In Table 1, the authors synthesized the total results of the 21 years of data that they collected from all 243 mentorship pairs who had implemented the model. The table's values identify the extent that mentor-protégé pairs matched or mismatched their respective self- and partner grid-placements. These placements represented partners' perceptions of the levels of their and their partners' respective mentoring responsibilities/behaviours related to the area of protégés' classroom management abilities.

Table 1: Degree of Match between Participants' Self- and Partner-Plotted Quadrant Locations on the AM Grids (Near the Conclusion of Practicum, N = 243 Pairs)

\begin{tabular}{|c|c|}
\hline \multicolumn{2}{|l|}{ Protégés' Developmental-level Grid Position } \\
\hline Degree of Matching & $\%$ \\
\hline Consistent match between partners' plotting & 87 \\
\hline Interns plotted selves higher than did cooperating teachers & 7 \\
\hline Interns plotted selves lower than did cooperating teachers & 6 \\
\hline \multicolumn{2}{|l|}{ Mentors' Adaptive-response Grid Position } \\
\hline Degree of Matching & $\%$ \\
\hline Consistent match between partners' plotting & 79 \\
\hline Cooperating teachers plotted selves higher than did interns & 12 \\
\hline Cooperating teachers plotted selves lower than did interns & 9 \\
\hline
\end{tabular}

Note. The values represent percentages of the pairs of mentors and protégés whose plottings of their own mentoring performance and that of their partners matched similar quadrants (e.g., A1 with D1, A2 with D2, and so forth). The competency being monitored was either classroom management or oral questioning. There were 99 pairs from 1993-1999, 40 pairs from 2000-2003, 28 pairs from 2004-2008, 76 pairs from 2010$2013 / 2014$.

\section{Overview}

If participants applied AM under ideal conditions, the authors assumed that the initial values in the upper and lower portions of Table 1 should have been $100 \%$. However, both the related literature (Rose Ragins \& Kram, 2007) and the authors' own research (Ralph \& Walker, 2011, 2013a) confirmed that interpersonal disagreements between mentorship partners can hamper progress. Table 1 indicates that agreement for pairs' ratings of protégés' D-levels was greater than their agreement for mentors' A-response levels. One explanation for this difference may be that participants were more knowledgeable about protégés' instructional skills than they were about partners' agreement about AM's mentoring actions, which they had only seen a few weeks earlier (Ralph, 205, p. 280).

\section{Protégé Developmental Level}

The values in the upper portion of Table 1 identify two sub-groups, who either overestimated or underestimated protégés' D-levels. An explanation for this 13\% sub-total may relate to differences between expert and novice teachers (Ralph, 2004, p. 159; 2005, p. 278).

Because experts have had more classroom experience, they have accumulated a broader instructional repertoire grounded in tested practice. Novices, however, possess limited choices and are typically more idealistic/unrealistic in their initial expectations (Fernandez, Dror, \& Smith, 2011). Furthermore, poor communication between mentoring partners could lead them to misunderstand/misinterpret events and responses (Tangen, Thompson, \& McCarthy, 2011).

\section{Mentor Adaptive Response}

The lower portion of Table 1 shows that pairs similarly mismatched their ranking of mentors' placements on the A-grid. Explanations for this mismatching may also relate to participants' relative unfamiliarity with AM and/or their lack of open communication.

\section{DISCUSSION}

The two "consistent-match" values shown in Table 1 are greater than those reported in the authors' earlier research (e.g., Ralph, 2002, p. 202), thereby suggesting that pairs' application of the AM model has improved over 
time. They attribute these gains to two refinements they have been making in their own modelling of AM usage with mentoring pairs. One refinement is that they are ensuring that the workshop-presentation introducing AM to each cohort is clear, compelling, and constructive, and the second is that they are deliberately and specifically referring to $\mathrm{AM}$ when addressing any mentoring element with pairs.

The authors' research has confirmed that AM's benefits are to clarify participants' conceptualization of the mentoring process and to help mentors divert potential conflicts by re-adjusting their respective behaviours to match each other's grid-positions. However, the ongoing challenge is to keep seeking ways to reduce the relatively small, but persistent, number of mismatches that seem to reappear in each cohort.

\section{AUTHOR INFORMATION}

Edwin Ralph, Ph.D., is a professor and internship-facilitator with the College of Education in the University of Saskatchewan in Saskatoon. His broad teaching and administrative experience informs his research interests in enhancing instruction and mentorship. E-mail: edwin.ralph@usask.ca (Corresponding author)

Keith Walker, Ph.D., is a professor with the College of Education and the Johnson Shoyama Graduate School of Public Policy at the University of Saskatchewan in Saskatoon. He has a wide range of teaching and administrative experience. E-mail: keith.walker@usask.ca

\section{REFERENCES}

1. Allen, T., \& Eby, L. (Eds.). (2007). The Blackwell handbook of mentoring: A multiple perspective approach. Malden, MA: Blackwell.

2. Burden, P., \& Byrd, D. (2012). Methods for effective teaching: Meeting the needs of all students (6 ${ }^{\text {th }}$ ed.). New York: Pearson.

3. Fernandez, R., Dror, I., \& Smith, C. (2011, January/February). Spatial abilities of expert clinical anatomists: Comparison of abilities between novices, intermediates, and experts in anatomy. Anatomical Sciences Education, 4(1), 1-8. Retrieved from http://onlinelibrary.wiley.com/doi/10.1002/ase.196/full

4. Hersey, P., \& Blanchard, K. (1988). Management of organizational behavior: Utilizing human resources $\left(5^{\text {th }}\right.$ ed. $)$. Englewood Cliffs, NJ: Prentice-Hall.

5. Kelly, M. (2007). What makes mentoring effective? Focal Point, 21(2), 19-21. Retrieved from http://www.academia.edu/229080/What_Makes_Mentoring_Effective_How_Research_Can_Guide_You_i n_Selecting_a_Program

6. Ralph, E. (1998). Developing practitioners: A handbook of contextual supervision. Stillwater, Oklahoma: New Forums Press.

7. Ralph, E. (2002). Mentoring beginning teachers: Findings from Contextual Supervision. Journal of Personnel Evaluation in Education, 16(3), 191-210.

8. Ralph, E. (2004). Developing managers' effectiveness: A model with potential. Journal of Management Inquiry, 13(2), 151-163.

9. Ralph, E. (2005). Enhancing managers' supervisory effectiveness: A promising model. Journal of Management Development, 24(3), 267-284.

10. Ralph. E., \& Walker, K. (2010). Enhancing mentors' effectiveness: The promise of the Adaptive Mentorship ${ }^{\oplus}$ model. Mc Gill Journal of Education, 45(2), 205-218. Retrieved from http://mje.mcgill.ca/index.php/MJE/article/view/4653

11. Ralph, E., \& Walker, K. (2011). Adapting mentorship across the professions: Fresh insights \& perspectives. Calgary, Alberta, Canada: Temeron/Detselig Publishers.

12. Ralph, E., \& Walker, K. (2013a). The efficacy of the Adaptive Mentorship model. Open Journal of Leadership, 2(2), 1-6. Retrieved from http://www.scirp.org/journal/PaperInformation.aspx?PaperID=32622

13. Ralph, E., \& Walker, K. (2013b). The promise of Adaptive Mentorship: What is the evidence? International Journal of Higher Education, 2(2), 76-85. Retrieved from http://dx.doi.org/10.5430/ijhe.v2n2p76

14. Rose Ragins, B., \& Kram, K. (Eds.). (2007). The handbook of mentoring at work: Theory, research, and practice. Los Angeles, CA: Sage. 
15. Roycroft, K. (2014, February). Mentoring for employment success: A review of the literature. Manchester, UK: Manchester Metropolitan University, Faculty of Education, Community Audit and Evaluation Centre. Retrieved from http://www.ioe.mmu.ac.uk/caec/reports/8252_Mentoring\%20for\%20Employment\%20 Report_screen2.pdf

16. Seeman, H. (2010). Preventing disruptive behavior in colleges: A campus and classroom management handbook for higher education. Lanham, Maryland: Rowman \& Littlefield.

17. Tangen, J., Thompson, M., \& McCarthy, D. (2011, August). Identifying fingerprint expertise. Psychological Science, 22(8), 995-997. doi: 10.1177/0956797611414729. Retrieved from http://pss.sagepub.com/content/22/8/995.short 